\author{
References \\ 1 De Boeck K, Kent L, Davies J, et al. CFTR biomarkers: time for promotion to surrogate end-point? Eur Respir J \\ 2013; 41: 203-216. \\ 2 Durmowicz AG, Witzmann KA, Rosebraugh CJ, et al. Change in sweat chloride as a clinical end point in cystic \\ fibrosis clinical trials: the ivacaftor experience. Chest 2013; 143: 14-18. \\ 3 Ramsey BW, Davies J, McElvaney NG, et al. A CFTR potentiator in patients with cystic fibrosis and the G551D \\ mutation. N Engl J Med 2011; 365: 1663-1672. \\ 4 Accurso FJ, Rowe SM, Clancy JP, et al. Effect of VX-770 in persons with cystic fibrosis and the G551D-CFTR \\ mutation. N Engl J Med 2010; 363: 1991-2003. \\ 5 Clancy JP, Rowe SM, Accurso FJ, et al. Results of a phase IIa study of VX-809, an investigational CFTR corrector \\ compound, in subjects with cystic fibrosis homozygous for the F508del-CFTR mutation. Thorax 2012; 67: 12-18. \\ 6 Suri R, Metcalfe C, Wallis C, et al. Assessing the usefulness of outcomes measured in a cystic fibrosis treatment trial. \\ Respir Med 2007; 101: 254-260. \\ 7 Brody AS, Sucharew H, Campbell JD, et al. Computed tomography correlates with pulmonary exacerbations in \\ children with cystic fibrosis. Am J Respir Crit Care Med 2005; 172: 1128-1132.
}

\title{
Allergic burden and the risk of venous thromboembolism
}

\author{
To the Editor:
}

We read with keen interest a recent article by MAJOOR et al. [1], who studied the relationship between asthma and venous thromboembolism (VTE). They provided evidence for the increased risk of VTE, specifically pulmonary embolism (PE), among asthmatics. In final regression models, after adjustment for potential confounders, MAJOOR et al. [1] found that body mass index was the sole independent predictor of deep vein thrombosis (DVT) risk, while only severe asthma and oral corticosteroid use independently predicted PE.

Mechanisms underlying the intriguing association of asthma with VTE remain unclear. However, several previous papers published by us and other investigators [2-5] showed that allergic diseases are associated with a number of prothrombotic alterations involving enhanced platelet activation, formation of dense fibrin clots that are relatively resistant to lysis, increased plasminogen activator inhibitor-1 levels or a disturbed protein $\mathrm{C}$ anticoagulant pathway. In a case-control study of subjects between 20 and 45 years old, we demonstrated that atopic diseases are more prevalent in patients with distal DVT, but not those with PE, and allergy to timothy grass pollen was over-represented in the VTE group [2]. Discrepancies in the patient characteristics and methodology between the current study [1] and ours [2] are likely to explain differences in the reported results.

The results by MAJOOR et al. [1] might also suggest that there are links between thrombosis and atopic sensitisation and/or allergic inflammation. Although less prevalent than in children, the atopic phenotype of asthma is common in adults, and $\geqslant 50 \%$ of adult asthmatics are positive for atopic sensitisation. The prevalence of other allergic diseases, such as atopic dermatitis and especially allergic rhinitis, which are quite common in the general adult population (about $2-10 \%$ and $20 \%$, respectively), is increased in asthmatics in whom, when present, they further increase the allergic inflammation burden. One might speculate that the overall allergic inflammation burden could have also contributed to the increased risk of VTE which MAJOOR et al. [1] observed in severe asthma. Although they included atopy in the final regression models, showing lack of its effect, it would be interesting to evaluate VTE risk in the subgroups obtained by stratification of asthma based on accompanying allergic diseases and/or atopy, similar to those they had conducted according to asthma severity. It is also possible that the lack of any association of atopy in the regression analyses could have resulted from a rather limited number of VTE events $(n=35)$ in the study by MAJOOR et al. [1].

Similarly, in this study, severe asthma showed the association with PE but not DVT and this observation might also be related to low numbers of PE $(n=19)$ and DVT $(n=16)$ events [1]. It cannot be excluded that DVT had been underestimated, which could have affected the results [1].

However, asthma has been independently reported to be associated with PE in a large retrospective primary care-based study by CAzzola et al. [6], although the DVT phenotype was not analysed in that study. 
Moreover, PE has been reported to occur more frequently than DVT in patients suffering from chronic obstructive pulmonary disease, which is associated with a moderately increased risk of VTE [7].

It is possible that the association between severe asthma and PE, but not DVT, reported by MAJOOR et al. [1] had a random component. However, if it is real, the differential effect of severe asthma on PE versus DVT occurrence might indicate that prolonged immobility and hospitalisation had no major impact on the VTE risk in this population, and allergic inflammation per se produces prothrombotic alterations, particularly if combined with the unfavourable effects of corticosteroids. Further investigations are needed to replicate the current findings by MAJOOR et al. [1] and to elucidate their pathogenetic mechanisms, both genetic and environmental, including a potential influence of allergy on thrombosis.

0 @ERSpublications

Recent epidemiological studies suggest that allergic diseases might increase the risk of venous thromboembolism http://ow.ly/mK82P

Daniel P. Potaczek ${ }^{1}$ and Anetta Undas ${ }^{1,2}$

${ }^{1}$ John Paul II Hospital, Krakow, and ${ }^{2}$ Institute of Cardiology, Jagiellonian University School of Medicine, Krakow, Poland.

Correspondence: D.P. Potaczek, John Paul II Hospital, 80 Pradnicka St, 31-202 Krakow, Poland. E-mail: d.potaczek@szpitaljp2.krakow.pl

Received: Jan 032013 | Accepted after revision: Jan 252013

Conflict of interest: None declared.

\section{References}

1 Majoor CJ, Kamphuisen PW, Zwinderman AH, et al. Risk of deep vein thrombosis and pulmonary embolism in asthma. Eur Respir J 2013; 42: 655-661.

2 Undas A, Cieśla-Dul M, Drążkiewicz T, et al. Association between atopic diseases and venous thromboembolism: a case-control study in patients aged 45 years or less. J Thromb Haemost 2011; 9: 870-873.

3 Nastałek M, Potaczek DP, Wojas-Pelc A, et al. Plasma platelet activation markers in patients with atopic dermatitis and concomitant allergic diseases. J Dermatol Sci 2011; 64: 79-82.

de Boer JD, Majoor CJ, van't Veer C, et al. Asthma and coagulation. Blood 2012; 119: 3236-3244.

Undas A, Potaczek DP, Nishiyama C, et al. Non-severe allergic asthma is associated with elevated plasma protein C and protein S. Thromb Haemost 2012; 107: 1000-1002.

6 Cazzola M, Calzetta L, Bettoncelli G, et al. Asthma and comorbid medical illness. Eur Respir J 2011; 38: 42-49.

7 Bertoletti L, Quenet S, Mismetti P, et al. Clinical presentation and outcome of venous thromboembolism in COPD. Eur Respir J 2012; 39: 862-868.

Eur Respir J 2013; 42: 1157-1158 | DOI: 10.1183/09031936.00000913 | Copyright @ERS 2013

From the authors:

We appreciate the suggestion by D.P. Potaczek and A. Undas that the overall allergic inflammation burden might have increased the risk of venous thromboembolism in our patients. Therefore, we performed a post hoc analysis in subgroups, after stratification for atopic and non-atopic asthma. But, again, we did not find any difference between the groups (table 1 ).

TABLE 1 Rate ratio $(95 \% \mathrm{CI}$ ) of first pulmonary embolism and deep-venous thrombosis (asthma population versus general population]

\begin{tabular}{lcc} 
& Non-atopic asthma & Atopic asthma \\
\hline $\begin{array}{l}\text { Subjects } \mathrm{n} \\
\text { All venous thromboembolism (definite } \\
\text { and probable) }\end{array}$ & 358 & 290 \\
$\quad \begin{array}{l}\text { Deep-vein thrombosis } \\
\quad \text { Pulmonary embolism }\end{array}$ & $1.60(0.44-4.09)$ & \\
$\begin{array}{l}\text { All definite venous thromboembolism } \\
\quad \text { Deep-vein thrombosis }\end{array}$ & $6.74(3.09-12.80)$ & $1.47(0.30-4.29)$ \\
$\quad$ Pulmonary embolism & $1.20(0.25-3.50)$ & $6.19(2.48-12.74)$ \\
& $6.75(3.09-12.83)$ & $1.47(0.30-4.30)$ \\
\end{tabular}

